\title{
Evaluating and improving the quality of risperidone prescribing
}

\author{
David Taylor, Robert Holmes, Trudi Hilton and Carol Paton
}

\begin{abstract}
Clinical studies suggest that risperidone is an effective antipsychotic with a low incidence of extrapyramidal adverse effects. In a prescription survey of several trusts, we found that risperidone was widely prescribed at high doses alongside typical neuroleptics and anticholinergic drugs. We also demonstrated that prescribing in a single trust can be improved by simple interventions. Risperidone should be prescribed as the sole antipsychotic at doses below $8 \mathrm{mg} / \mathrm{day}$ to realise fully its clinical advantages. Few prescriptions met this standard.
\end{abstract}

Risperidone was marketed in the UK in 1993 and is indicated for the treatment of positive, negative and affective symptoms of acute and chronic schizophrenia. It is said to give rise to a relatively low incidence of extrapyramidal side-effects (EPSE) and to improve negative symptoms of schizophrenia. These properties are held to be a result of a relatively greater affinity for type 2 serotonin receptors $\left(5-\mathrm{HT}_{2}\right)$ over $\mathrm{D}_{2}$ receptors (Livingstone, 1994).

Risperidone has been shown to be at least as effective as haloperidol in the treatment of positive symptoms of schizophrenia (Borison et al, 1992; Claus et al, 1992). The optimum dose (in those under 65 years of age) appears to be between $4 \mathrm{mg}$ and $8 \mathrm{mg} /$ day, with higher doses proving to be less efficacious (Chouinard et al, 1993; Peuskens, 1995). The results of some, but by no means all, studies have indicated that risperidone is particularly effective (that is more effective than either haloperidol or placebo) in ameliorating negative symptoms (Chouinard et ah 1993; Marder \& Meibach, 1994). Several studies have shown that the incidence of EPSE with risperidone at a low but therapeutic dose (6 mg/day) is not significantly different from placebo (Chouinard et al, 1993; Marder \& Meibach, 1994). Most studies also show that the need for anticholinergic medication is reduced accordingly.

It is thought that the absence of EPSE with atypical drugs may, at least in part, be responsible for the observed efficacy against negative symptoms (Carpenter et al, 1995). This reduced incidence of EPSE and the effect on negative symptoms appears to be lost at higher doses when the incidence of EPSE is similar to that produced by haloperidol (Marder \& Meibach, 1994; Peuskens, 1995).

All important studies addressing the efficacy and tolerability of risperidone have used risperidone as the sole antipsychotic. We are not aware of any data on its efficacy or tolerability when it is co-administered with other antipsychotics. Indeed, on theoretical grounds, the addition of $a D_{2}$ antagonist to risperidone therapy is likely to lessen, or even negate completely, the beneficial effect on EPSE and negative symptoms.

Risperidone is a relatively expensive drug but one with palpable and well-accepted advantages over older, traditional antipsychotics. To make its use cost-effective, prescribing practice should ensure that its benefits are fully realised. It seems clear that, in order to gain maximum benefit from the use of the drug, risperidone should be used as the sole antipsychotic in a dose of 4-8 mg/day (at least in those under 65). If used at these doses, the use of anticholinergic agents should usually be unnecessary.

We had observed, informally, that risperidone prescribing did not always conform to these ideals and to other recommendations from the manufacturer's data sheet (e.g. the need to increase the dose slowly) and so we sought in Study 1 to quantify the scale of the problem and in Study 2 to alter prescribing practices.

\section{The study}

\section{Study 1}

All prescriptions for risperidone presented to the pharmacy departments listed in the Acknowledgements during the second week of February 1996 were recorded. Medical notes were used in conjunction with prescription records to obtain the necessary data which were collected by pharmacists belonging to the South East Psychiatric Pharmacists Network, a regional component of the United Kingdom Psychiatric Pharmacy Group. Results were compared with the following standards derived from published literature on the efficacy and tolerability of risperidone. 
(a) The dose should be titrated up by $2 \mathrm{mg} /$ day starting from $2 \mathrm{mg}$ on the first day.

(b) The optimal treatment dose is $4-8 \mathrm{mg} /$ day (under 65) or 2-4 mg/day (over 65).

(c) Doses above $8 \mathrm{mg} /$ day increase the risk of EPSE.

(d) The concurrent use of other antipsychotics is likely to nullify or lessen the benefits of risperidone.

(e) Anticholinergic drugs should be unnecessary for risperidone doses below $8 \mathrm{mg} /$ day.

\section{Study 2}

This study took place at the Bethlem and Maudsley NHS Trust in south east London. The first review of the whole Trust, including prescriptions from the recently merged Warlingham Park Hospital, took place in September 1995. All pharmacists recorded details of all prescriptions including risperidone for one week. Data were then collated by T.H. and presented at the Trust's Drug and Therapeutics Committee meeting in October 1995. It was agreed by the committee that a letter would be sent to all prescribers stating the findings of this review. The letter also included advice on risperidone prescribing in line with the standards for risperidone use. All Trust pharmacists and the Trust's Drug Information Centre were asked to give similar advice when discussing therapy with prescribers. In addition, prescribers were notified whenever a prescription written by them did not conform to the agreed prescribing standards.

The prescription survey was repeated, using the same method, in December 1995 and February 1996. Data from the February 1996 review form part of the data for Study 1: the Bethlem and Maudsley was one of the twenty trusts surveyed.

\section{Findings}

\section{Study 1}

Data were gathered from 20 hospitals (see Acknowledgements), 12 of which had teaching status. The mean number of psychiatric beds per hospital was 172 (range 38-500), with 3434 beds in total. Overall, 267 patients were prescribed risperidone, $160(60 \%)$ men and $107(40 \%)$ women. Their mean age was 40.8 years (range 18-86). Of the total, 162 patients were under 65 years of age.

Place in therapy Risperidone was prescribed first line in $13(4.9 \%)$ of patients and at least second line in $227(85.0 \%)$. This information was not available for the remaining 27 (10.1\%) patients.
Dose titration Dosage titration, as recommended in the manufacturer's data sheet was followed in $188(44.2 \%)$ patients. It was not followed in $71(26.6 \%)$ of patients and information was not available for the remaining 78 (29.2\%).

Patients under 65 of the 162 patients aged under 65 who had received risperidone for more than two weeks (i.e. had completed dose titration), $43(26.5 \%)$ were prescribed more than $8 \mathrm{mg} /$ day. Only $76(47 \%)$ received risperidone as the sole antipsychotic. Concurrent anticholinergics were prescribed to 32 (20\% of those under 65) receiving risperidone as the sole antipsychotic. Patients prescribed risperidone as the sole antipsychotic in doses of $>8 \mathrm{mg} /$ day were significantly more likely to be receiving anticholinergic medication (eight patients were prescribed anticholinergics and three no anticholinergics) (Fischer's exact test, $P=0.03$, d.f. $=1$ ); for patients prescribed a risperidone dose of $\leqslant 8 \mathrm{mg} /$ day, 24 were receiving anticholinergic medication and 41 were not.

All patients Overall, 141 (53\%) patients were prescribed concurrent conventional neuroleptics, 88 (33\% of total sample) of whom also received anticholinergics. The number of patients who received concurrent anticholinergics along with risperidone as the sole antipsychotic was 54 ( $20 \%$ of total sample).

\section{Study 2}

The results of the three reviews are shown in Table 1.

Other neuroleptics were said to be 'coprescribed' if they were written on the prescription either for regular administration or when necessary' only. The same criteria were applied to prescriptions of anticholinergic drugs. The daily dose was said to be optimal if it was between 4 and $8 \mathrm{mg} /$ day (adults) or between 2 and $4 \mathrm{mg}$ (elderly). In Study 2, all but one of those not in this range were below the lower limit. The incremental dose is that recommended in the manufacturer's data sheet: $2 \mathrm{mg} /$ day on day one, $4 \mathrm{mg} /$ day on day two and $6 \mathrm{mg} /$ day on day three (halved doses in the elderly). In many cases, previous prescriptions were not available for review and details of incremental starting doses therefore not available. These cases were categorised as 'unclear'.

\section{Comments}

In Study 1, we found that risperidone prescribing in our sample was less than optimal in a number of areas: doses of $>8 \mathrm{mg} /$ day were 
Table 1. Results of the three prescription surveys

\begin{tabular}{|c|c|c|c|}
\hline & Yes & No & Unclear \\
\hline \multicolumn{4}{|l|}{ October $1995(n=45)^{\prime}$} \\
\hline $\begin{array}{l}\text { Other neuroleptics } \\
\text { co-prescribed }\end{array}$ & $49 \%$ & $51 \%$ & - \\
\hline $\begin{array}{l}\text { Anticholinergics } \\
\text { co-prescribed }\end{array}$ & $51 \%$ & $49 \%$ & - \\
\hline Optimal dosage & $80 \%$ & $20 \%$ & - \\
\hline $\begin{array}{l}\text { Incremental dose } \\
\text { schedule followed } \\
\text { December } 1995(n=45)\end{array}$ & $13 \%$ & $49 \%$ & $38 \%$ \\
\hline $\begin{array}{l}\text { Other neuroleptics } \\
\text { co-prescribed }\end{array}$ & $40 \%$ & $60 \%$ & - \\
\hline $\begin{array}{l}\text { Anticholinergics } \\
\text { co-prescribed }\end{array}$ & $40 \%$ & $60 \%$ & - \\
\hline Optimal dosage & $82 \%$ & $18 \%$ & - \\
\hline $\begin{array}{l}\text { Incremental dose } \\
\text { schedule followed } \\
\text { February } 1996(n=44)^{3}\end{array}$ & $29 \%$ & $13 \%$ & $58 \%$ \\
\hline $\begin{array}{l}\text { Other neuroleptics } \\
\text { co-prescribed }\end{array}$ & $30 \%$ & $70 \%$ & - \\
\hline $\begin{array}{l}\text { Anticholinergics } \\
\text { co-prescribed }\end{array}$ & $32 \%$ & $68 \%$ & - \\
\hline Optimal dosage & $93 \%$ & $7 \%$ & - \\
\hline $\begin{array}{l}\text { Incremental dose } \\
\text { schedule followed }\end{array}$ & $45 \%$ & $14 \%$ & $41 \%$ \\
\hline
\end{tabular}

1. Age range $18-82$ years, mean age $=38$ years.

2. Age range $18-75$ years, mean $a g \theta=39$ years.

3. Age range $18-80$ years, mean age $=38$ years.

being frequently used; risperidone was often co-prescribed with a traditional neuroleptic; anticholinergics were commonly co-prescribed; and incremental schedules were frequently not followed. Clinical trial data demonstrate that risperidone offers real advantages over conventional antipsychotics when employed as monotherapy in doses of $8 \mathrm{mg}$ or less per day. In clinical practice, however, it seems its benefits are not being realised.

In Study 2, the results of each of the surveys also highlighted a degree of inappropriate use of risperidone when local prescribing was compared to the agreed standards. However, the proportion of inappropriate prescriptions fell after remedial action by the Drug and Therapeutic Committee and this favourable trend was found to continue some months later.

Possible explanations for the apparently suboptimal use of risperidone include:

(a) Risperidone alone in doses of $8 \mathrm{mg} /$ day or less was not clinically effective in a proportion of patients (this is not supported by clinical trials (Peuskens, 1995)), leading to high doses being used and to the co-prescription of traditional neuroleptics. We recognise that optimal doses identified in trials do not always reflect optimal use in practice in an individual.

(b) The dose of risperidone was being titrated rapidly in early treatment in an attempt to produce clinically significant sedation. It is well established that antipsychotics do not produce immediate relief from core symptoms (Keck, 1989). Their use as general sedatives is inappropriate and has resulted in many patients receiving high dose regimes (Thompson, 1994).

(c) Prescribers were aware of prescribing recommendations (the data sheet recommends daily doses of up to $16 \mathrm{mg} /$ day), but not of the findings of clinical trials.

(d) Prescribers were not aware of prescribing recommendations for: risperidone in particular, as illustrated by the failure to follow the recommended dosage titration schedule in over a quarter of patients; and antipsychotics in general where monotherapy is considered to be good clinical practice (Thompson, 1994). Prescribing surveys repeatedly demonstrate that multiple neuroleptic prescribing is an important problem (Chaplin \& McGuigan. 1996).

(e) Prescribers did not realise that risperidone did not cause EPSE at low doses in clinical trials and prescribed anticholinergics through habit.

(f) Risperidone may cause EPSE at doses below $8 \mathrm{mg} /$ day in practice, thus necessitating the prescribing of anticholinergic medications. (Our data definitely indicates that EPSE are a problem at doses above $8 \mathrm{mg} /$ day.)

In Study 1 , less than $5 \%$ of patients had been prescribed risperidone as a first line antipsychotic. The use of risperidone as second or third line therapy may well be a reflection of the common practice of prescribing risperidone for refractory schizophrenia. While second line use may be appropriate in those patients who fail to tolerate conventional antipsychotics due to EPSE or who have severe negative symptoms, we are not aware of any published evidence from well-conducted, double-blind clinical trials to suggest that risperidone is effective in treatment resistant illness. Case reports have been published which describe both success (Avnon \& Kunin, 1995) and failure (Mok \& Yatham, 1994). A naturalistic study (Keck et al, 1995), reporting on the progress of 144 consecutive patients treated with risperidone concluded that $11 \%$ (3 of 27) of those who had been in hospital for over one year responded sufficiently to risperidone to 
allow discharge from hospital. It is not possible to conclude from such a small number of patients, with poorly defined treatment resistant illness and outcome, that this response rate is any greater than the $5 \%$ seen when sequential trials of typical antipsychotics are used (Kane et al, 1988). Clinical experience, however, indicates that response rates to risperidone are much below the 30\% response rates reported for acute treatment with clozapine (Kane, 1988). Recognition of this may go some way to explaining the use of high-dose risperidone and/or concurrent neuroleptics which we have observed.

In Study 1, our sample of 267 patients cost over $£ 400000$ per year to treat. Only $15 \%$ received risperidone as monotherapy in doses of $8 \mathrm{mg}$ or less per day and without concurrent anticholinergics. The majority received risperidone under less ideal circumstances where objective evidence of efficacy is lacking.

While both studies revealed a poor quality of risperidone prescribing. Study 2 did at least show that prescribing practice can be improved. Simple measures were found to be effective in substantially improving the quality of risperidone prescribing. Taken together, these two studies have shown that risperidone prescribing is less than optimal in a number of respects. perhaps leading to wastage of scarce funds. Educational initiatives appear to affect favourable change and they should be used where audit identifies deficiencies in prescribing.

\section{Acknowledgements}

We thank the pharmacy departments involved in the data collection: Royal Hospitals/Tower Hamlets Healthcare NHS Trust, Forest Healthcare, Ravensbourne NHS Trust, Riverside Mental Health NHS Trust, Parkside Health, Guy's and Lewisham Mental Health Trust, Oxleas NHS Trust, Thameslink, Hounslow and Spelthorne Community and Mental Health Trust (Ashford and the West Middlesex), Eastbourne and County Healthcare Trust, Chase Farm Hospital NHS Trust, Newham Community Health Services NHS Trust, Camden and Islington Community Trust (St Luke's, UCLH and St Pancras), St Ann's NHS Trust. The Bethlem and Maudsley NHS Trust and South Bedfordshire Community Healthcare NHS Trust.

\section{References}

AVNon, M. \& KunIN, A. (1995) Risperidone response after no clozapine response (letter). British Journal of Psychiatry. 167. 699.

Borison, R. L., PATHIRAJA, A. P., DIAmond, B. I., et a (1992) Risperidone: clinical safety and efficacy in schizophrenia. Psychopharmacology Bulletin. 28. 213-218.

CARPENTER, W. T. CONLEY, R. R., Buchanan, R. W., et al (1995) Patient response and resource management: another view of clozapine treatment of schizophrenia. American Joumal of Psychiatry, 162, 827-832.

Chaplin, R. \& McGuigan, S. (1996) Antipsychotic dose: from research to clinical practice. Psychiatric Bulletin. 20. $452-454$.

Chouinard, G., Jones, B. REMington, G et al (1993). A Canadian multicenter placebo-controlled study of fixed doses of risperidone and haloperidol in the treatment of chronic schizophrenic patients. Journal of Clinical Psychopharmacology. 13, 25-40.

Claus, A., BOllen, J.. DE CUYPer. H., et al (1992) Risperidone versus haloperidol in the treatment of chronic schizophrenia in-patients: a multicentre double-blind comparative study. Acta Psychiatrica Scandinavica, 85. 295-305.

KANE, J. M., Honingfeld, G., Singer, J., et al (1988) Clozapine for the treatment of resistant schizophrenia. Archives of General Psychiatry. 46. 789-796.

KECK. P. E., CoHEN, B. M., BALDESSARINE, R. J., et al (1989) Time course of antipsychotic effect of neuroleptic drugs. American Joumal of Psychiatry, 146. 1289-1292.

-. WiLson. D. R. STRAKOWSK, S. M., et al (1995) Clinical predictors of acute risperidone response in schizophrenia, schizoaffective disorder, and psychotic mood disorders. Journal of Clinical Psychiatry. 66, 466470.

LivingSTON, M. G. (1994) Drug profile - risperidone. Lancet. 343, $457-460$.

MARDER. S. R. \& MEIBACH. R. C. (1994) Risperidone in the treatment of schizophrenia. American Journal of Psychiatry. 161, 825-835.

MоK. H. \& YATHAM. L. N. (1994) Response to clozapine as a predictor of risperidone response in schizophrenia. American Journal of Psychiatry, 181, 1393-1394.

PEUSKENS, J. (1995) Risperidone in the treatment of patients with chronic schizophrenia: a multi-national. multi-centre, double-blind, parallel-group study versus haloperidol. British Joumal of Psychiatry. 166. 712-726.

THOMPSON, C. (1994) The use of high-dose antipsychotic medication. British Joumal of Psychiatry. 164, 448-458.

*David Taylor, Chief Pharmacist, Bethlem and Maudsley NHS Trust, London SE5 8AZ; Robert Holmes, Principal Pharmacist, Royal London Hospital (Mile End), Bancroft Road, London E1 4DG; Trudi Hilton, Principal Pharmacist, Ealing Hospital, Uxbridge Road. Middlesex UB1 3HW: and Carol Paton, Chief Pharmacist, Bexley Hospital, Old Bexley Lane, Bexley DA5 2BW

\section{*Correspondence}

